\title{
Stress and Coping Strategies among Undergraduate Nursing Students in Calabar, Nigeria
}

\author{
Patience Edoho Samson-Akpan ${ }^{1}$, Mildred Edet John², Olaide Bamidele Edet ${ }^{3}$, \\ Regina Etita Ella ${ }^{4}$ \\ 'FWACN, RN/RM, RNT,PhD Associate Professor \\ ${ }^{2} F W A C N$, RN/RM, RNT, Ph.D. Professor \\ ${ }^{3} F W A C N, R N / R M, P h D$ Associate Professor \\ ${ }^{4} F W A C N$, RN/RM, RNT, Ph.D. Senior Lecturer \\ Department of Nursing Sciences, Faculty of Allied Medical Sciences, College of Medicine, University of \\ Calabar. Calabar, Cross River State, Nigeria
}

\begin{abstract}
:
Background: Evidence reveals that undergraduate nursing students experience moderate to high level of stress. Some of the stressors that affect students are pressure of academics due to intense desire to succeed, anxiety about future outcome and inability to integrate into the educational system. Therefore, the main aim of the study was to assess the level of stress and the coping strategies used by the undergraduate nursing students in Calabar, Nigeria.

Methods: A descriptive cross sectional study using a simple random sampling technique was adopted to select a sample of 154 students. The instrument for data collection was "Perceived Stress Scale (PSS) and Nursing Students Coping Orientation for Problems" (NUSCOPE). Statistical analysis involved descriptive statistics and One-way analysis of variance.

Results: The mean age of the respondents was 28.91 \pm 7.61 ; majority were females 136(88.3\%).The mean of perceived stress within the last one month was $39.12 \pm 7.08$ while some of the respondents $73(47.4 \%)$ experienced low level of stress, others 81(52.6\%) had high level of stress. The most commonly used coping strategies were: seeking diversion $27.73 \pm 4.27$; self-reliance 18.05 \pm 3.43 ; avoiding $17.71 \pm 3.90$. One way analysis of variance showed that there was a significant difference between the level of study and the level of stress $(p<0.05)$ while there was no statistically significant difference with regards to mode of entry and the level of stress $(p<0.05)$.

Conclusion: The study points to the need for stakeholders to design programmes that will reduce stress, health educate and encourage the students to utilize healthy coping strategies focusing on problem solving to promote health.
\end{abstract}

Keywords: Stress, Coping strategies, Undergraduate nursing students, Level of study, mode of entry

\section{Background}

Stress is a "state produced by a change in the environment that is perceived as challenging, threatening, or damaging to a person's dynamic balance or equilibrium" (Smeltzer, Bare, Hinkle \& Cheever, 2010). Stressors are the events or situations change or stimulus that evokes stress. Previous studies have classified stressor into three main categories: "academic pressures, social issues and financial pressures" (Fisch, 1996). Generally, different kinds of stressors affect students such as the pressure of academics with the responsibility to succeed, not knowing the future outcome and inability to integrate into the system. Students grapple with social, emotional, physical and family problems which may interfere with academic performance(Shamar \& Kaur, 2011). Stress can have both positive and negative effects on nursing students impacting onboth thinking and learning(Gibbons, Dempster \& Moutray, 2008; Seyedfatemi, 2007). However, despite the harmful effects of persistent high levels of stress (Nicholl \& Timmins, 2005) it is reported that low levels of stress also act as a motivator for the nursing students (Sindir \& Acarolu, 2008).

Previous studies highlighted increased levels of distress and related negative impactsamong medical(Dahlin, Joneborg \& Runeson, 2005) and nursing students (Pheukphan, 2009)such as symptoms of depression(Moreira \& Furegato, 2013).The possible negative impact of emotional distress as reported in literature among medical students includeimpairment in teaching learning processes and clinical performance, stress induced disorders, and diminishing performance (Malathi \& Damoradan, 1999). Furthermore, exposure to persistent high level of stress in academic environment may induce physical problems influencing students' selfesteem and academic achievement (Nicholl, \& Timmins, 2005). College and undergraduate nursing students experience similar stressors related to academics namely: midterm and final examinations, writing seminar and 
presentation / clinical reports/ research papers and other assignments. Another source of stress peculiar to nursing students is the clinical components of the educational programme. Nursing students have to be fully prepared for the clinical experience on the wards and community settings which is accompanied with a lot of anxiety (Evans \& Kelly, 2004).

Students worry about working with dying patients or patients with terminal diseases, interpersonal conflicts with nurses, problem of incompetency, fear of making mistakes or failure, relating effectively with the patients and their relations, work overload and the outcome of nursing care to the patient (Pryjmachuk\&Richards, 2007; Rejesh Kumar, 2007). Furthermore, other sources of stress for the nursing students includes: unrealistic deadlines for submission of assignment, unclear assignments, excessive homework, un-conducive learning environments and poor interpersonal relationship with faculty members (Amr, El-Gilany, El-Moafee, Salama, \& Jimenez, 2011; Rejesh Kumar, 2007; Shamar \& Kaur 2011; Eswi, Radi, \& Youssri, 2013).

Stress as auniversal phenomenon affects other college students as well as nursing students whether in the degree programme or diploma programmes. A descriptive study on stress and coping strategies using a total of 180 nursing students in a private nursing institute in Pujab, affiliated to Baba Farid University of Health Science;(Rejesh Kumar, 2007)reported moderate stress among 34\% of the students, with 33\% mild and severe stress respectively. Dhar, Walia, and Das, (2009) also carried out a descriptive study to assess the causes of stress and coping strategies used by the newly admitted BSc. Nursing students, it was reported that $48.83 \%$ had mild stress and $11.62 \%$ had moderate stress. A related study by Shamar and Kaur (2011) using 37 nursing students in a private nursing institute in Pujab, affiliated to Baba Farid University of Health Science, also revealed that $97 \%$ of the participants had moderate level of stress with $3 \%$ having severe stress. Khater, AkhuZaheya and Shaban, (2014)reported on the perceived stress level among 597 Jordanian nursing students and it was discovered that $286(47.82 \%)$ had stress level above mean. Severe level of stress was also reported by Abasimi, Atindanbila, Mahamah, and Gai (2015) among nursing students in nursing training colleges in Tamale, Ghana which may portend depression. In affirmation of the reported studies above, Samson-Akpan, John Edet and Kalu (2016) reported that 56(88.9\%) and 61(96.8\%) of the participants said academic stress and interpersonal stress were very much part of their lives in a university in South-South Geopolitical Zone in Nigeria.

Mode of entry refers to the entry points by the prospective students in to the universityto register for any academic programme offered by the university. There are three modes of entry into the undergraduate nursing programme in Nigeria (Bachelor of Nursing Science Programme): Unified Tertiary Matriculation Examination (UTME) (generic), Direct Entry (Registered Nurses without degree) and transfers from other universities within and outside the country. Literature reveals that the mode of entry can mediate on the level of stress experienced by the nursing students. In a related studyDeck and Srivastava (1991)in School of Nursing, Memorial University of Newfoundland, St. John, Canada where participants were separated into Registered Nurse and generic groups; the results showed that while the two groups in the study experienced stress, generic students reported significantly higher levels of stress.

Another factor that can influence the level of stress among nursing students is the students' level of study. In a related study on factor associated with stress among nursing students in Saudi Arabia using a selfreported questionnaire, the results showed that nursing students in their third year exhibited the highest stress level more than students in other years of study(Aedh, Elfaki, Mohamed, 2015). In a longitudinal study which compared differences between academic years (Zupiria et al. (2007) discovered no significant differences between the types of stressors in different levels of the degree programme.

One of the skills that an undergraduate nursing student should develop is learning to cope with stress which is necessary for every day's life and nursing career. Coping is the ability to appraise the stressful situation with the goal of adaptation or adjustment to the change in order to regain balance and develop the power and ability to meet new challenges(Smeltzer et al., 2010). It is necessary to set priorities, plan ahead and organize oneself so as to reduce the negative consequence of stress.Coping comprises of cognitive and behavioural efforts put in to ensure that the specific external and internal demands that deplete individual resources are containedor managed, and this may be classified as "emotion focused" or "problem focused coping". The terms emotion focused and problem focused coping were used by Lazarus and Folkman, (1984)to describe the "cognitive and behavioural efforts" a person uses to manage stress. Coping which is emotion-focus ensures that the individual feels better by reducing the emotional distress whereas problem-focused coping main purpose is to make direct changes in the environment so that the threatening situation can be managed more appropriately and effectively.

Students utilize many coping strategies such as "ventilation, diversion, relaxation, self-reliance, social peer group support, avoidance, praying, day dreaming, listening to music and smoking, drinking, joking" among others(Seyedfatemi, 2007, Samson-Akpan et al. 2016).Rejesh Kumar (2007) reported that majority of the respondents in her study totalling 180 nursing students in a private nursing institute in Pujab, affiliated to Baba 
Farid University of Health Science, use good adaptive measures as compared to maladaptive ones. "Seeking diversion" was mostly used while seeking "professional support" was the least common coping strategy utilized by nursingstudents (Rejesh Kumar, 2007; Samson-Akpan et al. 2016).Pheukpan (2009) also highlighted that self-reliance and humour were used by nursing students in Australia (AU) to manage stress while according to Khater, Akhu-Zaheya and Shaban, (2014), Jordanian baccalaureate nursing students used mainly "problem solving as a coping measure". However, Alzayyat and Al-Gamal (2014) in a literature review on stress and coping among students during practical education in psychiatric settings found that students continuously use ineffective coping strategies in managing clinical stressors.

Stress cannot be removed from nursing students daily experiences be it academic, interpersonal and environmental but management of stress through utilization of appropriate coping strategies ensures students' health promotion, better quality of life and positive impact on academic performance. Studies within and outside the country have examined stress among medical students, radiographic students (Ugwu and Ugwumba, 2013), student nurses (Rejesh Kumar, 2007; Shamar \& Kaur 2011) undergraduate nursing students in Egypt Amr, ElGilany, El-Moafee, Salama, \& Jimenez (2011) but there is no study in Nigeria addressing undergraduate nursing students' stress and coping strategies. This study will provide empirical evidence on the level of stress among nursing students in the university and if it is high, intervention will be carried out to reduce stress and this study will also address the paucity of literature on stress among nursing students in Nigeria.

The study was aimed at:

a) Assessing the level of perceived stress among undergraduate nursing students in Calabar, Nigeria.

b) Identifying the coping strategies used by undergraduate nursing students in Calabar, Nigeria

Two null hypotheses were developed for testing:

i. There is no significant association between mode of entry and the level of stress among undergraduate nursing students in Calabar, Nigeria.

ii. There is no significant difference in the level of study and the level of stress among undergraduate nursing students in Calabar, Nigeria.

\section{Design and setting}

A descriptive cross sectional study was carried outto ascertain the level of stress and coping strategies used by nursing undergraduate students. The setting of the study wasCalabar; Calabar is located in the rain forest belt in the Eastern parts of Nigeria. The city houses two Local Government Areas (LGAs): Calabar South Local Government Area and Calabar Municipality. Calabar is the capital of Cross River State and it is located on a Peninsula between Calabar River and the great Kwa River. The study was carried out in the the Department of NursingScience, University of Calabar, Calabar, Nigeria. The University has the responsibilities of manpower development (teaching) and promotion of scientific knowledge (research). This site was selected because it is the only major tertiary institution in Calabar that offers nursing at degree and post graduate level.

\section{Study population}

The study population consisted of all nursing students totalling 527 in the Nursing Science Department.However, students in 300 to 500 levels were used for the study. These students were selected because it is in their third to fifth year that most of the nursing courses are offered. Therefore, proportionate samplings of $50 \%$ of students in all strata (300 to 500 levels) were used. Therefore, a simple random sampling method with replacement was used to select the 154 students out of 308 which constitute $50 \%$ of the respondents. In order to select the 154 respondents, a list of all registered students in year 3-5 was collected from the department administration. Two research assistants helped in writing 'yes' or 'no' on a paper which were folded and completely mixed in a bag where theResearch Assistants had to pick. The students who had yes picked against their names were selected until a fixed number $(50 \%)$ from each class or level was chosen. Difficulty in accessing a student necessitated another balloting for replacement until $50 \%$ for each class was attained. The only inclusion criterion was being in level three to five.

\section{Instrument for data collection}

The instruments used for data collection were: Respondents' characteristic (profile) sheet, Perceived Stress Scale (PSS) developed byCohen, Kamarek and Mermelstein (1983)and Nursing Students Coping Orientation for Problems (NUSCOPE) modified from Adolescent Coping Orientation for Problem Experiences (ACOPE).The characteristics of the respondents coveredby the instrument were age, gender, mode of entry, level of student, distance from the campus, residential status, marital status, mother's educational status, father's educational status, mothers' income, father's income, mothers' occupation and father's occupation. PSS has 14 items on a Likert Scale. This tool was used to ascertain the level of perceived stress of undergraduate nursing students which centred on their feelings and cognition in the last one month. PSS is a 5-point Likert scale ranging from $0=$ Never, $1=$ Almost never, $2=$ Sometimes, $3=$ Fairly often, and $4=$ Very often. This instrument was 
modified by the researchersafter pre-testingto ensure that it was sensitive to the needs of the students. The items were increased from 14 to 15 . The item that was added was 'thinking about the target to be met'. This item was added based on the request of the students and in consultation with a specialist in measurement and evaluation. This particular item addressed students' peculiar needs in the environment of the study. The current (modified PSS) instrument had a content validity index of 0.87 and a test retest reliability of the instrument revealed a correlation coefficient (r) 0.78. The score ranged from 0-60 (the lowest score in the Likert Scale was 0, while the highest score of 4 in the Likert Scale was multiplied by 15 items $=60$ ). ACOPE wasdeveloped by Patterson, $\&$ McCubbin, (1987). NUSCOPE was utilized to examine the coping strategies used by undergraduate nursing students in order to overcome stress. It was a five-point Likert Scale ranging from $0=$ Never, $1=$ Hardly, $2=$ Sometimes, $3=$ often and $4=$ Most of the time. It had 12 sections with 55 modified items. NUSCOPE content validityindex was 0.80 while a test retest reliability of the instrument was 0.82 .

\section{Data collection}

Nursing students who were in 300-500 level of study in the department were approached in their classeson different days for permission to be involved in the study. The students who accepted to participate in the study were given consent forms to fill and returned to the researchers, the purpose of the study was explained to them and the instrument for data collection was administered on them. Data collection was done face to face by the researchers and two research assistants. The data collection was done during break periods and on the spot retrieval of the administered copies of questionnaire ensured that all completed copies of the questionnaire were collected on the same day. Data collection lasted for one week.

\section{Data Analysis}

Data were analysed using SPSS version 20. Statistical analysis utilised descriptive statisticsChi Square and One-way analysis of variance for hypothesis one and two. The stated hypotheses were tested at 0.05 level of significance. The overall score obtainable on the stress scale was 75 . If the score is greater than 38 , the respondent was classified as having high level of stress otherwise the stress level is classified as low.

\section{Ethical consideration}

The study proposal was forwarded to Health Research Ethics Committee of the University of Calabar Teaching Hospital and permission was given to carry out the study. Furthermore, written permission was obtained fromUniversity of Calabar, Head of Department of Nursing Science, and the students. The purpose of the study was made explicit to all concerned. Each copy of the questionnaire was assigned number and there was no provision for names of the participants to ensure anonymity. All information from the respondents were kept confidential and only used for research purposes. The study did not pose any threats to the respondents. Used copies of the questionnaire were stored in a locked cupboard for confidential purposes.

\section{Results}

The characteristics of respondents showed the mean age of the respondents was $28.91 \pm 7.61$; majority of the respondents were females $136(88.3 \%)$ and were never married 83(53.9). The mode of entry revealed that majority of the respondents came into the university through Unified Matriculation Examination 88 (57.1\%) while direct entry were 63 (40.9\%); most of the respondents were in 500 level $60(39 \%)$ followed by those in 400 level 52(33.8\%). Majority of the respondents were living off campus $132(82.7 \%)$.

Table 1shows the level of perceived stress within the last one month and it revealed that some of the respondents $60(49.9 \%)$ 'never' had confidence about ability to handle personal problems while 89 (57.8) 'never' thought about the target to be met. More than $40 \%$ of the respondents said that 'sometimes' they were upset that something happened unexpectedly, felt unable to control important issues in their lives, felt nervous and stressed, felt that things were going their own way, felt unable to manage all things that should be done, felt that they were in control, felt angry because things were happening outside their control, and were able to manage their time.The mean of perceived stress within the last one month was $39.12 \pm 7.08$. The results also revealed that out of the 154 respondents, $73(47.4 \%)$ had low level of stress while $81(52.6 \%)$ had high level of stress. 
Table 1 Responses to perceived stress within the last one month among undergraduate nursing students in Calabar, Nigeria

\begin{tabular}{|c|c|c|c|c|c|c|c|}
\hline$s / n$ & Items & Never & Almost & Some- & Fairly often & Very & Total \\
\hline 1 & Being upset that something happened & & $\frac{\text { nev }}{12}$ & $\frac{\operatorname{tim}}{92}$ & & $\frac{\text { often }}{17(11.0)}$ & $154(100)$ \\
\hline 1 & 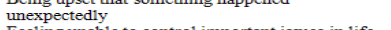 & & $(7.8)$ & $(59.7)$ & $(9.7)$ & $17(11.0)$ & $134(100)$ \\
\hline 2 & Feeling unable to control important issues in life & $\begin{array}{l}10 \\
(6.5)\end{array}$ & $\begin{array}{l}17.0) \\
(11.0)\end{array}$ & $\begin{array}{l}71 \\
(46,1)\end{array}$ & $24(15.6)$ & $32(20.8)$ & $154(100)$ \\
\hline 3 & Feeling nervous and stressed & 28 & 32 & & $10(6.5)$ & & $154(100)$ \\
\hline 4 & Able to deal successfully with day to day & 52 & 45 & & & & $154(100)$ \\
\hline 5 & $\begin{array}{l}\text { probbems or challenges } \\
\text { Feeling effectively coping with important }\end{array}$ & 39 & $\begin{array}{ll}(29.3 \\
54\end{array}$ & 48 & ${ }_{7}^{(5.2)}$ & & $154(100)$ \\
\hline 6 & $\begin{array}{l}\text { challenges that were occurring in life } \\
\text { Feeeling confident about ability to handle personal }\end{array}$ & $\begin{array}{l}(25 . \\
63\end{array}$ & $(35$. & $\begin{array}{c}(31.2 \\
46\end{array}$ & ${ }_{5}^{(4.5)}$ & $(3.9)$ & $154(100)$ \\
\hline & problems & $(40$. & $(21.4)$ & 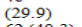 & $(3.2$ & $(4.5$ & $184(100)$ \\
\hline r & Feeling that things were goir & & $(30$. & $62(40.3)$ & $11(7.1)$ & $17(11.0)$ & $154(100)$ \\
\hline 8 & $\begin{array}{l}\text { Feeling unable to manage all things that should be } \\
\text { done }\end{array}$ & & $28(18.2)$ & $75(48.7)$ & $25(16.2)$ & $17(11.0)$ & $154(100)$ \\
\hline 9 & Able to control irritation in life & 38 & $40(26.0)$ & $55(25.7)$ & $13(8.4)$ & & $154(100)$ \\
\hline 10 & Feeling that $\mathrm{I}$ am in control & 28 & $33(21.4)$ & $62(40.3)$ & $16(10.4)$ & $15(9.7)$ & $154(100)$ \\
\hline 11 & Feeling angry because things were happening & & $27(17.5)$ & $65(42.3)$ & & & $154(100)$ \\
\hline 12 & $\begin{array}{l}\text { outside my control } \\
\text { Thinking about the task to be accomplished }\end{array}$ & & $35(22.7)$ & $44(28.6)$ & & & $154(100)$ \\
\hline 13 & Able to manage my time & 31 & $42(27.3)$ & $66(42.9)$ & $10(6.5)$ & & $154(100)$ \\
\hline 14 & Feeling that challenges would not be overcome & & & $40(26.0)$ & $40(20.6)$ & & $154(100)$ \\
\hline 15 & Thinking about the target to be met & 89 & $20(13.0)$ & $32(20.8)$ & (A & 6 & $154(100)$ \\
\hline
\end{tabular}

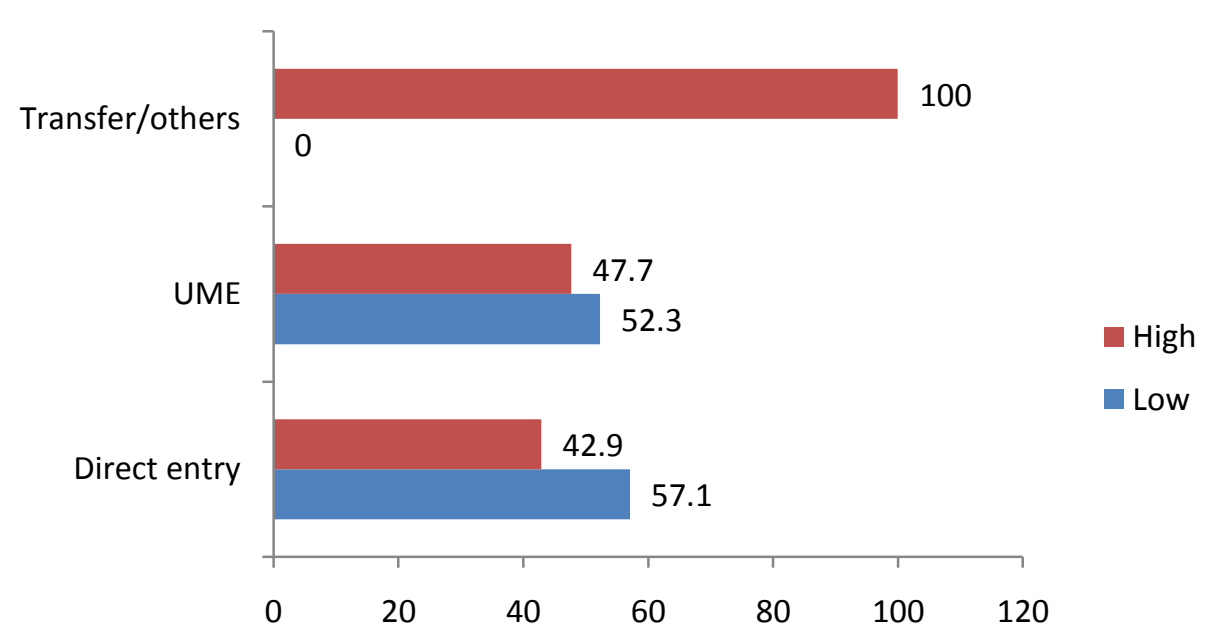

Figure 1: Mode of entry and level of perceived stress

In Figure 1, results reveals that of the 63 who entered through direct entry, 36 (57.1) had low level of stress and $27(42.9 \%)$ had high level of stress. For UME, $47.7 \%$ reported high level of stress while all who were transferred reported high level of stress.

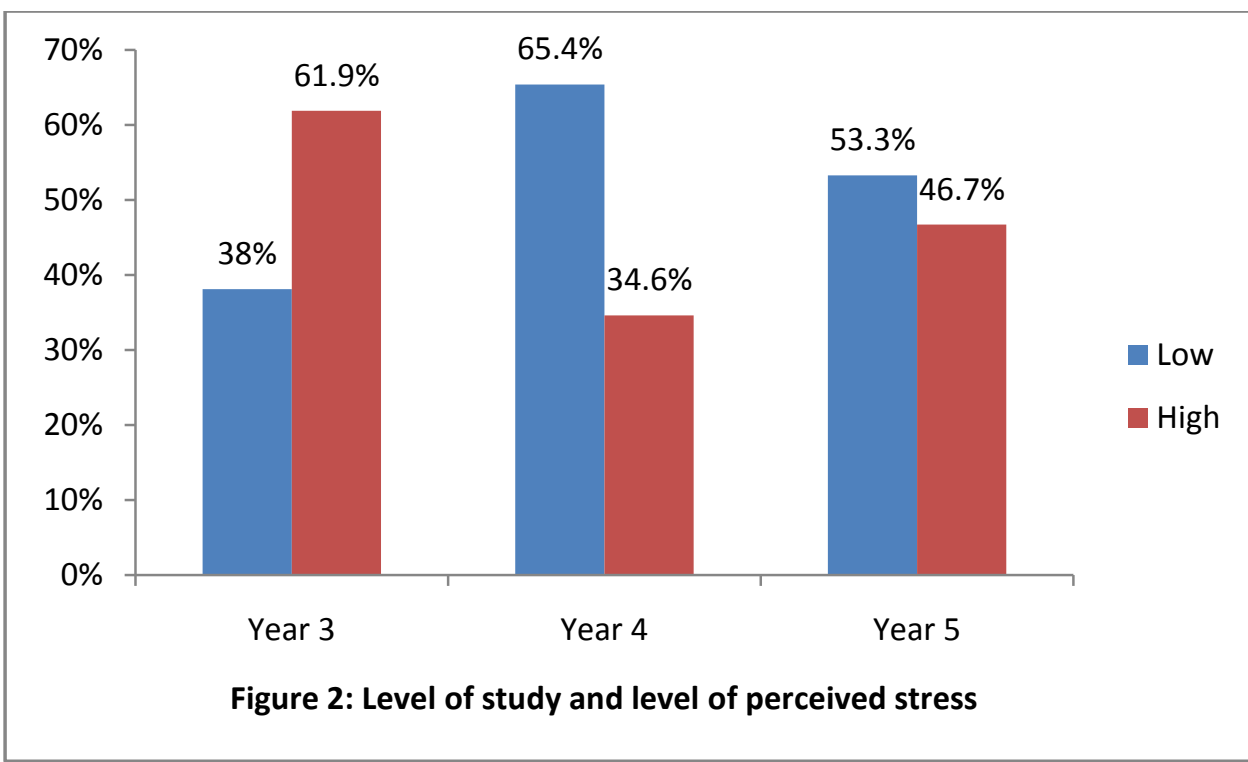


Results in Figure 2 shows that 26 (61.9\%) of the respondents in year 3 had high level of stress. The prevalence of high stress among year 4 and year 5 obtained was $34.6 \%$ and $46.7 \%$ respectively. These results imply that the majority who reported high level of stress were year 3 students.

Table 2Coping strategies utilized by undergraduate nursing students in Calabar, Nigeria

\begin{tabular}{|c|c|c|c|c|c|c|}
\hline Items & Never & Hardly & sometimes & Often & $\begin{array}{l}\text { Most of the } \\
\text { time }\end{array}$ & Total \\
\hline \multicolumn{7}{|l|}{ Ventilating feelings } \\
\hline Say mean things to people & $10(6.5)$ & $7(4.5)$ & $37(24.0)$ & $49(31.8)$ & $51(33.1)$ & $154(100)$ \\
\hline Swear & $5(3.2)$ & $8(5.2)$ & $24(15.6)$ & $45(29.2)$ & $72(46.8)$ & $154(100)$ \\
\hline Let off steam by complaining to your friends & $20(13.0)$ & $13(8.4)$ & $82(53.2)$ & $28(18.2)$ & $11(7.1)$ & $154(100)$ \\
\hline Get angry and yell at people & $11(7.1)$ & $5(3.2)$ & $47(30.5)$ & $56(36.4)$ & $35(22.7)$ & $154(100)$ \\
\hline \multicolumn{7}{|l|}{ Seeking diversion } \\
\hline Go to movie & $10(6.5)$ & $13(8.4)$ & $58(37.7)$ & $38(24.7)$ & $35(22.7)$ & $154(100)$ \\
\hline Play video games & $8(5.2)$ & $14(9.1)$ & $46(29.9)$ & $42(27.3)$ & $44(28.6)$ & $154(100)$ \\
\hline Use drugs & $15(9.7)$ & $9(5.8)$ & $29(18.8)$ & $19(12.3)$ & $82(53.2)$ & $154(100)$ \\
\hline Listen to music & $35(22.7)$ & $37(24.0)$ & $40(26.0)$ & $15(9.7)$ & $27(17.5)$ & $154(100)$ \\
\hline Read & $29(18.8)$ & $36(23.4)$ & $62(40.3)$ & $18(11.7)$ & $9(5.8)$ & $154(100)$ \\
\hline Go shopping & $27(17.5)$ & $25(16.2)$ & $55(35.7)$ & $33(21.4)$ & $14(9.1)$ & $154(100)$ \\
\hline Watch TV & $17(11.0)$ & $26(16.9)$ & $78(50.6)$ & $21(13.6)$ & $12(7.8)$ & $154(100)$ \\
\hline Sleep & $21(13.6)$ & $42(27.3)$ & $65(42.6)$ & $16(10.2)$ & $10(6.5)$ & $154(100)$ \\
\hline Chatting online & $25(16.2)$ & $31(20.1)$ & $60(39.0)$ & $24(15.6)$ & $14(9.1)$ & $154(100)$ \\
\hline \multicolumn{7}{|l|}{ Relaxing } \\
\hline Work on a hobby & $16(10.2)$ & $26(16.9)$ & $67(43.5)$ & $22(14.3)$ & $23(14.9)$ & $154(100)$ \\
\hline Eat food & $11(7.1)$ & $27(17.5)$ & $61(39.6)$ & $27(17.5)$ & $28(18.2)$ & $154(100)$ \\
\hline Day dream & $9(5.8)$ & $28(18.2)$ & $44(28.6)$ & $29(18.8)$ & $44(28.6)$ & $154(100)$ \\
\hline \multirow{2}{*}{\multicolumn{7}{|c|}{ Self-reliance }} \\
\hline & & & & & & \\
\hline Get a part time job & 23 (14.9) & $23(14.9)$ & $39(25.3)$ & $20(13.0)$ & $49(25.3)$ & $154(100)$ \\
\hline Work harder & $36(23.4)$ & $52(33.8)$ & $36(23.4)$ & $13(8.4)$ & $17(11.0)$ & $154(100)$ \\
\hline Try to think of good things & $41(26.6)$ & $64(41.6)$ & $30(19.5)$ & $8(5.2)$ & $11(7.1)$ & $154(100)$ \\
\hline Try to make your own decision & $60(39.0)$ & $48(31.2)$ & $35(22.7)$ & $3(1.9)$ & $8(5.2)$ & $154(100)$ \\
\hline Organize what you have to do & $43(27.9)$ & $44(28.6)$ & $42(28.6)$ & $20(13.0)$ & $5(3.2)$ & $154(100)$ \\
\hline \multicolumn{7}{|l|}{ Get more involve in extra-curricular } \\
\hline activities & $24(15.6)$ & $28(18.2)$ & $58(37.7)$ & $34(22.1)$ & $10(6.5)$ & $154(100)$ \\
\hline \multicolumn{7}{|l|}{ Tell yourself that those problems are not } \\
\hline important & $33(21.4)$ & $21(13.6)$ & $51(33.1)$ & $26(16.9)$ & $23(14.9)$ & $154(100)$ \\
\hline \multicolumn{7}{|l|}{ Developing social support } \\
\hline Blame others for what is going on & $21(13.6)$ & $22(14.3)$ & $45(29.2)$ & $26(16.9)$ & $40(26.0)$ & $154(100)$ \\
\hline Apologize to people & $37(24.0)$ & $44(28.6)$ & $48(31.2)$ & $14(9.1)$ & $11(7.1)$ & $154(100)$ \\
\hline Try to help other people solve their problems & $36(23.4)$ & $47(30.5)$ & $53(34.4)$ & $11(7.1)$ & $7(4.5)$ & $154(100)$ \\
\hline Try to keep friendship or make new friends & $36(23.4)$ & $50(32.5)$ & $52(33.8)$ & $13(8.4)$ & $3(1.9)$ & $154(100)$ \\
\hline Say nice things to others & $39(25.3)$ & $56(36.4)$ & $50(32.5)$ & $4(2.6)$ & $5(3.2)$ & $154(100)$ \\
\hline Talk to friends about how you feel & $29(18.8)$ & $40(26.0)$ & $69(44.8)$ & $9(5.8)$ & $7(4.5)$ & $154(100)$ \\
\hline \multicolumn{7}{|l|}{ Solving family problems } \\
\hline Talk to your father about what bothers you & $26(16.9)$ & $32(20.8)$ & $57(37.0)$ & $22(14.3)$ & $17(11.0)$ & $154(100)$ \\
\hline Try to reason with parents and talk things out & $36(23.4)$ & $36(23.4)$ & $63(40.9)$ & $11(7.1)$ & $8(5.2)$ & $154(100)$ \\
\hline Go along with parents' request & $34(22.1)$ & $35(22.7)$ & $66(42.9)$ & $14(9.1)$ & $5(3.2)$ & $154(100)$ \\
\hline Do things with your family & $34(22.1)$ & $57(37.5)$ & $50(32.5)$ & $8(5.2)$ & $5(3.2)$ & $154(100)$ \\
\hline Talk to siblings about how you feel & $29(18.8)$ & $37(24.0)$ & $63(40.9)$ & $11(7.1)$ & $14(9.1)$ & $154(100)$ \\
\hline $\begin{array}{l}\text { Talk to your mother about what bothers you } \\
\text { Avoiding }\end{array}$ & \multicolumn{5}{|c|}{ Avoiding } & $154(100)$ \\
\hline Smoke & $25(16.2)$ & $12(9.8)$ & $17(11.0)$ & $9(5.8)$ & $91(59.1)$ & $154(100)$ \\
\hline Use medications & $20(13.0)$ & $10(6.5)$ & $20(13.0)$ & $20(13.0)$ & $84(54.5)$ & $154(100)$ \\
\hline $\begin{array}{l}\text { Try to stay away from home as much as } \\
\text { possible }\end{array}$ & $14(9.1)$ & $29(18.8)$ & $33(21.4)$ & $26(16.9)$ & $52(33.8)$ & $154(100)$ \\
\hline Try to see good things & $24(15.6)$ & $31(20.1)$ & $46(29.9)$ & $16(10.4)$ & $37(24.0)$ & $154(100)$ \\
\hline Drink beer, wine liquor & $18(11.7)$ & $21(13.6)$ & $43(27.9)$ & $16(10.4)$ & $56(36.4)$ & $154(100)$ \\
\hline \multicolumn{7}{|l|}{ Seeking spiritual support } \\
\hline Talk to a minister, prophet, or prophetess & $24(15.6)$ & $37(24.0)$ & $44(28.6)$ & $27(17.5)$ & $22(14.3)$ & $154(100)$ \\
\hline Go to church & $50(32.5)$ & $56(36.4)$ & $27(17.5)$ & $10(6.5)$ & $11(7.1)$ & $154(100)$ \\
\hline Pray & $47(30.5)$ & $52(33.8)$ & $17(11.0)$ & $8(5.2)$ & $30(19.5)$ & $154(100)$ \\
\hline Seek traditional healer's help & $19(12.3)$ & $34(22.1)$ & $19(12.3)$ & $13(8.4)$ & $69(44.8)$ & $154(100)$ \\
\hline \multicolumn{7}{|l|}{ Investing in close friends } \\
\hline Be close to someone you care about & $36(23.4)$ & $42(27.3)$ & $55(35.7)$ & $6(3.9)$ & $15(9.7)$ & $154(100)$ \\
\hline Be close with a boyfriend or girlfriend & $24(15.6)$ & $23(14.9)$ & $62(40.3)$ & $24(15.6)$ & $21(13.6)$ & $154(100)$ \\
\hline \multicolumn{7}{|l|}{ Seeking professional support } \\
\hline Get professional counselling & $24(15.6)$ & $24(15.6)$ & $51(33.1)$ & $39(25.3)$ & $16(10.4)$ & $154(100)$ \\
\hline $\begin{array}{l}\text { Talk to student's academic advisor about } \\
\text { your concerns }\end{array}$ & $21(13.6)$ & $16(10.4)$ & $48(31.2)$ & $40(26.0)$ & $29(18.8)$ & $154(100)$ \\
\hline Engage in demanding activities & & & & & & \\
\hline $\begin{array}{l}\text { Do a strenuous physical activity } \\
\text { Try to figure out how to deal with problems }\end{array}$ & $21(13.6)$ & $26(16.9)$ & $56(36.4)$ & $34(22.1)$ & $17(11.0)$ & $154(100)$ \\
\hline
\end{tabular}




\begin{tabular}{|c|c|c|c|c|c|c|}
\hline and tensions & $33(21.4)$ & $59(38.3)$ & $44(28.6)$ & $15(9.7)$ & $3(1.9)$ & $154(100)$ \\
\hline $\begin{array}{l}\text { Try to improve yourself (get better grades, } \\
\text { look good etc.) }\end{array}$ & $57(37.5)$ & $52(33.8)$ & $33(21.4)$ & $10(6.5)$ & $2(1.3)$ & $154(100)$ \\
\hline $\begin{array}{l}\text { Work hard on school work or projects } \\
\text { Being humorous }\end{array}$ & $52(33.8)$ & $61(39.6)$ & $37(24.0)$ & $3(1.9)$ & $1(.6)$ & $154(100)$ \\
\hline Joke and keep a sense of humour & $44(28.6)$ & $62(40.3)$ & $42(27.3)$ & $4(2.6)$ & $2(1.3)$ & $154(100)$ \\
\hline Try to be funny and take things lightly & $52(33.8)$ & $47(30.5)$ & $48(31.2)$ & $6(3.9)$ & $1(.6)$ & $154(100)$ \\
\hline
\end{tabular}

Results in Table 2 shows coping strategies used by the respondents. Most of the respondents ventilated feelings through letting off steam by 'sometimes' complaining to friends $82(53.2 \%)$ and swearing 'most of the time' $72(46.8 \%)$. Regarding seeking diversion, more than $40 \%$ of the respondents watched TV, slept and read. The respondents also relaxed by 'sometimes' working on a hobby $67(43.5 \%)$ and eating food $61(39.6 \%)$. Under self-reliance, some of the respondents 60(39\%) never tried to make their own decisions while 64 (41.6\%) 'hardly' try to think of good things.

With regards to developing social support as a coping strategy, most of the respondents 69 (44.8\%), 'sometimes' talk to friends about how they feel and 'hardly' say nice things to others 56 (36.4\%). Solving family problems is one of the coping strategies, many respondents 66 (42.9\%) 'sometimes' tried to go along with parents' request; 63(40.9\%) try to reason with parents and talk things out and 63(40.9\%) talked to siblings about how they felt. With regards to using avoiding as a coping strategy, most of the respondents smoked $91(51.1 \%)$ and used medications $84(54.5 \%)$ 'most of the time.'

Some of the respondents $56(36.4 \%)$ 'hardly' go to church or pray $52(33.8 \%)$ as a means of seeking spiritual support. Many respondents $62(40.3 \%)$ 'sometimes' became close to boy or girlfriend when investing on close friends as a coping strategy. Regarding seeking professional support, 'sometimes' most of the respondents 51(33.1\%) got professional counselling and 'hardly' work hard on school work or project $61(39.6 \%)$ or tried to figure out how to deal with the problems or tensions $59(38.3 \%)$ when engaging in demanding activities as a coping strategy. Lastly,most of the respondents 'hardly' joked and kept a sense of humour 62(40.3\%).

Further analysis of results showed the weighted mean values of the most commonly used coping strategies were seeking diversion (27.72 \pm 4.27 ), self-reliance (18.04 \pm 3.43$)$, avoiding (17.70 \pm 3.90$)$, solving family problems (15.95 \pm 6.43$)$, developing social support (15.05 \pm 3.37$)$ ventilating feelings $(14.55 \pm 2.81)$, and relaxing (13.41 \pm 3.03$)$. Other coping strategies in descending order are spiritual support (11.05 \pm 2.31$)$, engaging in demanding activities $(9.16 \pm 2.86)$, seeking professional support (6.23 \pm 2.07$)$, investing on friends $(5.48 \pm 1.89)$ and the least utilized coping strategy was being humorous $(4.07 \pm 1.63)$

\section{Ho1Mode of entry and level of stress}

There is no significant association between mode of entry and the level of stress among undergraduate nursing students in Calabar, Nigeria.

The results also showed that Chi-Square calculated of $X^{2}$ cal. 3.834was less than the $X^{2}$ crit of 5.99 at 0.05 level of significance ( $\mathrm{p}$ - value $=0.147$ ) with 2 degrees of freedom. The null hypothesis was not rejected. Therefore, there is no significant association between mode of entry and level of stress.

\section{Ho 2 Level of study and level of stress}

There is no significant difference in the level of study and the level of stress among undergraduate nursing students in Calabar, Nigeria.

The $\mathrm{X}^{2}$ cal. of 5.99 at 0.05 level of significance of significance with 2 degrees of freedom and $\mathrm{P}<0.05$ $(0.03<0.05)$. Therefore, the null hypothesis is rejected. Therefore, there is a significant association between level of study and the level of stress $(\mathrm{p}<0.05)$.

Table 3One-way ANOVA and Post Hoc LSD on mode of entry and the level of stress among undergraduate nursing students in Calabar, Nigeria $(\mathrm{N}=154)$

\begin{tabular}{|l|l|l|l|l|l|l|l|}
\hline Categories & $\mathrm{N}$ & Mean & SD & Fcal & Fcrit & p-value & Remarks \\
\hline Direct & 63 & $38.17^{\mathrm{a}}$ & 7.04 & 4.81 & 3.06 & 0.009 & $*$ \\
\hline UME & 88 & $39.38^{\mathrm{a}}$ & 6.88 & & & & \\
\hline Transferred & 3 & $50.67^{\mathrm{b}}$ & 5.13 & & & & \\
\hline
\end{tabular}

$d f_{1}=2 \quad$ and $\quad d f_{2}=151$ 
The results in Table 3 is significant $(p<0.05)$. Similar letter mean not significantly different while different letters means significantly different $(\mathrm{p}<0.05)$. This result implies that there is a significant difference in transferred students' level of stress whereas UME and direct entry are not significantly different.

Table 4One- way ANOVA Post Hoc LSD -Year of study on the level of stress among undergraduate nursing students in Calabar, Nigeria $(\mathrm{N}=154)$

\begin{tabular}{|l|l|l|l|l|l|l|l|}
\hline Categories & $\mathrm{N}$ & Mean & SD & Fcal & Fcrit & p-value & Remarks \\
\hline Year 3 & 42 & $41.83^{\mathrm{b}}$ & 8.11 & 4.73 & 3.06 & 0.010 & $*$ \\
\hline Year 4 & 52 & $37.58^{\mathrm{a}}$ & 6.19 & & & & \\
\hline Year 5 & 60 & $38.52^{\mathrm{a}}$ & 6.63 & & & & \\
\hline
\end{tabular}

$d f_{1}=2 \quad$ and $\quad d f_{2}=151$

The resultsin Table 4 is significant $(\mathrm{p}<0.05)$. Similar letter mean not significantly different while different letters means significantly different $(\mathrm{p}<0.05)$. This result implies that there is a significant difference in year 3 with regards to level of stress whereas year 4 and 5 are not significantly different.

\section{Discussion}

The study focussed on the level of perceived stress and coping strategies utilized by undergraduate nursing students. The results revealed that $47.4 \%$ of the respondents had low level of stress while $52.6 \%$ had high level of stress. The study affirmed that nursing students experience low and high level of stress as reported by (Moreira \& Furegato, 2013; Shamar \& Kaur, 2011; Sindir \& Arcrolu, 2008; Rajesh Kumar, 2011; Dhar, Walia, \& Das, 2009; Abasimiet al., 2015; Samson-Akpan et al. 2016). However, the percentage of students who experiencedmoderate and high stress according to (Moreira \& Furegato, 2013; Shamar \& Kaur, 2011; Rajesh Kumar 2011; Khater, Akhu-Zahya, 2014)was lower than the one reported in this study where most of the respondents experienced high levels stress. This revelation may be attributed to the respondents' lack of confidence to handle personal problems and also more than $40 \%$ of the respondents in this study said that 'sometimes' they were upset that something happened unexpectedly, felt unable to control important issues in their lives, felt nervous and stressed, felt unable to manage all things that should be done, felt angry because things were happening outside their control, and were able to manage their timeaveragely. Nevertheless, Rajesh Kumar (2011)posits that challenges associated with nursing curriculum had always been a source of stress during the entire period of training of the nursing students.

Findings also revealed that $42.9 \%$ of the direct entry students had high level of stress while $47.7 \%$ of those respondents who came through UME, reported high level of stress and all who were transferred also reported high level of stress. The finding of this study is supported byDeck \& Srivastava (1991) that both registered nurses and generic students experience stress but generic students reported significantly higher levels of stress. The high level of stress among respondents who came into the nursing programme through UTME or transferred from another university or another programme within the university is expected because of fear of unknown and also most of the time they are less experienced than those who are Registered Nurses. The direct entry students who are registered nurses who wish to have additional qualification of Bachelor of Nursing Science are always matured students with some years of practical experience which give them a level of confidence in the programme of study than the UTME and the transferred students. However, further analysis of the results revealed that there was no significant association between mode of entry and level of stress.

The results of the study also showed that majority of the respondents in year $3(61.9 \%)$ had high level of stress against year 4 and year 5 with $34.6 \%$ and $46.7 \%$ respectively. Additional findings highlighted a significant difference in year 3 with regards to level of stress whereas year 4 and 5 were not significantly different.The findings are in support Rajesh Kumar (2011) and Aedh, Elfaki, \& Mohamed (2015) studies. Dhar, Waliaand Das (2009)reported that the stress level of first year and third year B.Sc. Nursing Students was found to be significantly higher than other classes. Aedh, Elfaki, \& Mohamed (2015) also studied factors associated with stress among nursing student in Saudi Arabia, the study utilised a convenient sample of 50 students using a self-reported questionnaire; the results showed that nursing students in their third year experienced higher levels of stress than nursing students in other years. The findings in this study is not surprising because it is in 300 level of the five year programme and 200 level of the four year programme that nursing students start offering nursing courses rather than general sciences courses offered in 100 level and basic medical science courses offered in 200 level. However when they passed from 300 level to 400, they become more settled for the nursing courses with reduced initial anxiety.

One of the skills that an undergraduate nursing student should develop is learning to cope with stress which is necessary for every day's life and nursing career. Coping is the ability to appraise the stressful situation with the goal of adaptation or adjustment to the change in order to regain equilibrium and develop the energy and ability to meet new demands (Smeltzer et al., 2010)The current study also identified the most frequently 
used coping strategies in descending order: seeking diversion, self-reliance, avoiding, solving family problems, developing social support, ventilating feelings and relaxing. These coping strategies identified support the findingsof Seyedfatem (2007) and Samson-Akpan et al. (2016) who identified various coping strategies used by nursing students in Iran and Nigeria.These coping strategies included the followings: ventilation, diversion, relaxation, self-reliance, social peer group support, avoiding, praying, day dreaming, listening to music and smoking, drinking, joking among others.Pheukphan (2009) also highlighted that self-reliance was used by nursing students to manage stress which affirm the findings in this study. Furthermore, it was surprising that more than half of the respondents in this study smoked (51.1\%) and used medications (54.5\%) 'most of the time' as a means of managing stress. The use of smoking and medication is a maladaptive coping strategy. Therefore, for students who have done pharmacology and are knowledgeable on the harmful effect of substance abuse, it then raises concern about their values, health and wellbeing.However, Alzayyat \& Al-Gamal (2014) in a literature review on stress and coping among students during practical education in psychiatric settings found that students continuously use ineffective coping strategies in managing clinical stressors, although this study addressed undergraduate nursing students perceived stress using a global tool.

Others coping strategies used by the respondents in this study included spiritual support, engaging in demanding activities, seeking professional support, investing on friends and being humorous as the last option.Seeking diversion by nursing students as a coping strategy is in consonant with Rajesh Kumar (2011) and Samson-Akpan et al. (2016)findings. Relatedly, being humorous as the least used coping strategy is supported bySeyedfatemi (2007) study among Iranian nursing students; but inconsistent with the findings that solving family problems was themost used. The result of this study showed that seeking professional support is one of the coping strategies that had lower mean score, the result is incongruent with the findings of Rajesh Kumar (2011) and Samson-Akpan et al. (2016) that it is the least coping strategy used by nursing students in the study.

Seeking professional support is one strategy that should be used by student because they are all assigned to academic advisers who are in a position to offer support to alleviate their problems but observations and interactions in this study revealed that the students prefer to relate with their peer groups and friends than seeking help from academic advisers. It is worthy of note that the present study brought to the forefront the revelation that the respondents 'hardly' work hard on school work or project $(39.6 \%)$ or tried to figure out how to deal with the problems or tensions (38.3\%) when engaging in demanding activities. These findings are not in consonant with Aedh, Elfaki, \& Mohamed (2015)which revealed that most of the nursing students used problem solving as coping measure. Working on school projects or assignment and trying to figure out how to deal with problems which may result in accomplishing school objectives can reduce anxiety, therefore, when students hardly engage in these activities it implies more stress.

\section{Conclusion and Conclusion}

- It was concluded that more than half of the respondents suffered from high levels of stress.

- Respondents who came through UME ortransferred from other departments and universities suffered high level of stress than direct entry students

- Respondents who were in 300 level had higher levels of stress than 400 and 500 levels students.

- There is a significant relationship between level of study and level of stress experienced by the students

- Most frequently used coping strategies in descending order: seeking diversion, self-reliance, avoiding, solving family problems, developing social support, ventilating feelings and relaxing.

Therefore, these recommendations were proffered for the identified areas of needs:

- Education and encouragement of students on the use appropriate and healthy coping strategies since stress is a chronic and pervasive condition affecting everybody with the nursing student not excluded from the experience of stress.

- Proper orientation of students who transfer or come into the department through UME; this exercise helps to reduce anxiety as students are oriented to their expectations from the academic and non-academic activities and staff including what is expected of them.

- Highlight on the harmful effect of substance abuse and the use of maladaptive coping strategies should be addressed during orientation.

- Academic students' adviser should devise a means of making themselves more accessible to students and the stakeholders should encourage the students to use their academic advisers inorder to benefit from their wealth of experience in counselling. If there is need for professional counsellors, the faculty should ensure that appropriate arrangements are made for consultation in order to reduce students' stress.

\section{Acknowledgement}

The researchers acknowledge and appreciate the Health Research and Ethics Committee of the University of Calabar Teaching Hospital for approval to carry out the study andmonitoring to ensure that ethical principles were adhered to. Furthermore, we also thank the Head of Department of Nursing Science and the 
management of University of Calabar for permitting us to use the students. We appreciate the students for voluntary participation in the study.It would have been a very limited study if only the authors' ideas were presented, therefore, we thank the different authors whose write up have been used in the study.

\section{Competing interests}

The authors hereby declare that there is funding from any source for this study and there is no competing interests

\section{References}

[1]. Abasimi, E., Atindanbila, S., Mahamah, M. M., \& Gai, X. (2015). The experience of stress among nursing students in nursing colleges in Tamale, Ghana. International Journal of Psychology and Behavioural Sciences, 5(2), 89-97

[2]. Aedh, A. I., Elfaki, N. K., \& Mohamed, I. A. (2015). Factors associated with stress among nursing students (Najran University Saudi Arabia). IOSR Journal of Nursing and Health Science (IOSR-JNHS). 4(6), 33-38.

[3]. Alzayyat, A., \& Al-Gama,1 E. (2014). A review of literature regarding stress among nursing students during the clinical education. Int Nurs Rev. 61:405-15 doi:10.1111/inr12114. Epub 2014 Jun 5.

[4]. Amr, M., El-Gilany, A., El-Moafee, H, Salama, L.,\& Jimenez, C. (2011). Stress among Mansoura (Egypt) baccalaureate nursing students. The Pan-African Medical Journal. 8: 26. Available:http://www.panafrican-med-journal.com/content/article/8/26/full.

[5]. Cohen, S. T., Kamarek T. \& Mermelstein, R. (1983). A global measure of perceived stress. Journal of Health and Social Behaviour. 24, 385-396

[6]. Dahlin, M., Joneborg, N.,\& Runeson B. (2005). Stress and depression among medical students: a cross sectional study. Med Educ. 39, 594-604

[7]. Deck D. L., \&Srivastava, R. (1991). Perceived level and sources of stress in a baccalaureate nursing students. Journal Nurse Education. 30(3), 127-133

[8]. Dhar, R., Walia, I.,\&Das, K. A. (2009). Descriptive study to assess the causes of stress and coping strategies used by the newly admitted basic B.Sc. nursing students. Nursing and Midwifery Research Journal 5 (1); 31-37

[9]. Eswi, A. B., Radi, S., \&Youssri H. (2013). Stress/stressors as perceived by Baccalaureate Saudi Nursing Students. Middle-East Journal of Scientific Research. 14(2):193-202

[10]. Evans, W., \&Kelly, B. (2004). Pre-registration diploma students nurse stress and coping measures. Nurse Education Today 24(6), 473-482.

[11]. Fisch, N. M. A. (1996).Health students in college environment. Public Health Nursing, 104-11

[12]. Gibbons, C., Dempster, M., \& Moutray, M. (2008). stress and eustress in nursing students. Journal of Advance Nursing, 61(83), 282-290.

[13]. Khater, W.A., Akhu-Zaheya, L. M., \& Shaban, I. A. (2014). Sources of stress and coping behaviour in clinical practice among baccalaureate nursing students. International Journal of Humanities and Social Science, 4(6), 194-202

[14]. Lazarus R. S., \& Folkman S (1984). Stress appraisal and coping. New York: Springer

[15]. Malathi, A., \&Damoradan, A. (1999). Stress due to exams in medical students - role of Yoga. Indian Journal of Physiol. Pharmacol. 43, 218-24

[16]. Moreira, D. P., \& Furegato, A. R. F. (2013). Stress and depression among students of the last semester in two nursing $\begin{array}{lllll}\text { courses.Revista Latino-Americana de } & \text { Enfermagem. } & \text { 21(Jan/Feb) }\end{array}$ http://www.scielo.php?script=sci_arttex\&pid=S0104-11692013000700020

[17]. Nicholl, H., \& Timmins, F. (2005). Programmed-related stressors among part-time undergraduate nursing students. Journal of Advanced Nursing. 50(1), 93-100

[18]. Patterson, J. M.,\& McCubbin H I. (1987). Adolescents coping style and behaviour - conceptualization and measurement. Journal of Adolescent. 10(2), 163-186.

[19]. Pheukphan, A. P. (2009). Stress and coping strategies among AU (Australian) nursing students. Available from http://www.nurse.au.edu/

[20]. Pryjmachuk, S., \& Richards, D. A. (2007). Predicting stress in pre-registration nursing students. British Journal of Health Psychology, 12, 125-144.

[21]. Rajesh Kumar, N. (2011). Stress and coping strategies among nursing students. Nursing and Midwifery Research Journal, 7(4), $141-151$.

[22]. Samson-Akpan, P. E., John, M. E., Edet, O. B., \& Uka , V. K. (2016). Undergraduate nursing students' experiences with stress in Nigeria. Poster presentation during College of Nursing International Nursing Research Conference, 6-8 April, 2016. University Edinburgh, Scotland.

[23]. Shamar, N.,\& Kaur, A. (2011). Factors associated with stress among nursing students. Nursing and Midwifery Research Journal. $7(1): 12-21$

[24]. Seyedfatemi, N. Tafreshi, M., \& Hagani, H. (2007). Experienced stressors and coping strategies among Iranian nursing students. BMC Nursing 6(1) Available at http:/ww.bimedical.com/

[25]. Sindir, M., \& Acarolu, R. (2008). Reliability and validity of Turkish version of clinical learning. Journal of Nursing Education, 28(6), 737-743

[26]. Smeltzer SC, Bare BG, Hinkle, JL, Cheever, KH. Brunner and Suddarth's textbook of medical-surgical nursing. (12 ${ }^{\text {th }}$ ed.) New York, USA: Wolters Kluwer Health/Lippincott Williams \& Wilkins; 2010, 79-81 p.

[27]. Ugwu UEC, Ugwumba, IJ. Stress among radiography students in Nigeria: A survey. Unique Research Journal of Medical Sciences. 2013; 1(3): $021-028$

[28]. Zupiria X., et al. (2007). Stress sources in nursing practice. Evolution during nursing training. Nurse Educator Today. 27: 777-787 